\title{
Single and Multiphase Compulsator System Architectures: a Practical Comparison
}

\author{
Jonathan R. Kitzmiller, John A. Pappas, and Siddartha B. Pratap \\ The University of Texas at Austin Center for Electromechanics \\ Mircea D. Driga \\ Electrical and Computer Engineering, The University of Texas at Austin
}

\begin{abstract}
The Center for Electromechanics at the University of Texas at Austin (UT-CEM) has designed, built, and tested three generations of iron-core and air-core compensated pulsed alternators (CPA). These include the iron core, small caliber, cannon caliber, and model scale compulsators. Early CPA were single-phase machines that were optimized for a specific load and desired performance. The most recent machine, the modelscale CPA, is a multiphase alternator coupled to the load through a rectifier. This paper includes a discussion of the requirements and capabilities of both single-phase and multiphase systems, a point design for each system type, and a comparison of system performance in driving a cannon caliber launcher.
\end{abstract}

\section{INTRODUCTION}

C.om OMPENSATED pulsed alternators (also called compulsators) are high-performance generators designed to discharge into a short circuit. Compulsator (CPA) operation requires that the magnetic coupling between armature and field windings be optimal and that a compensating winding act to compress the flux between coils, thereby lowering the internal impedance of the generator. The compensating function may be fulfilled by the armature winding, the field winding, or an additional shorted winding. CPA may have ferromagnetic or nonferromagnetic materials in the flux path; a machine without iron in the flux path is an air-core CPA. The peak flux density in a typical air-core CPA exceeds $2 \mathrm{~T}$. The need to remove iron from the flux path in high-field alternators has led to the use of advanced composite materials in both the rotor and the stator.

The iron-core compulsator [1] was the first step by the U.S. Army toward realizing a pulsed power supply for a compact and fieldable electric gun. This initial system, however, weighed nearly $12,000 \mathrm{~kg}$ and thus was still far from being adaptable to modern armored systems. The first air-core CPA (small caliber [2] and Task-C [3] systems) used advanced composite materials and incorporated self-excitation to increase power density. The small caliber system was built to

Manuscript received December 21, 1999. Funding for this effort was provided by the U.S. Army under contract DAAA21-92-C-0105. The COTR was Dr. Ed Schmidt. completion, but it was tested to less than its full design specification before its was removed from service.

The design of the cannon caliber electromagnetic gun system (CCEMG)[4] was based on experience gained from iron-core and air-core CPA development, and was the first railgun and power supply designed and built from a system perspective:

- the system performance requirement was based on projectile penetration

- specifications for each component came from the basic requirement and the interaction of each component with other subsystems

As a result, the CCEMG represented another step toward increased CPA power density. While the CCEMG was being tested, design and development work was begun on a multiphase CPA and railgun system, the model scale CPA [5, 6], which has been operated at the highest power density demonstrated by a CPA to date. This paper uses the information and experience gained during those developments to examine the advantages and disadvantages of single and multiphase CPA systems designed to drive a cannon caliber class load. The two systems under comparison are the rotating-field single-phase (RFSP) CPA and the rotating-field four-phase (RFFP) CPA. The system comparisons are based on the preliminary design of single- and multiphase systems that include technological advancements made in the previous development programs. Both systems will also be compared to the original CCEMG system.

\section{ASSUMPTIONS USED IN THE POINT DESIGNS AND COMPARISONS}

A tactical railgun system will be composed of the major items shown in the block diagram of Fig. 1. The major system components include the CPA, power converters, field initiation module (FIM), auxiliaries, electrical bus, and discharge controller. The FIM, auxiliaries, and electrical bus are all about the same size and weight for a given performance requirement, so they are ignored for the purposes of the system comparison. The reliability of the system depends upon the complexity of the controller, which is different for each type of CPA; therefore, controller issues 
must be included in the comparison.

Two advancements made since the design of CCEMG have been included in the design of both the RFSP and RFFP. The CCEMG compulsator has a titanium stator and a stationary field winding. The RFSP and RFFP each have a compositematerial stator and a rotating field capable of storing enough energy for several shots and of handling the heat load for that number of shots inertially. In addition, each system was designed with the assumption that it would drive the CCEMG series-augmented railgun that would fire a $185 \mathrm{~g}$ launch package at $1,850 \mathrm{~m} / \mathrm{s}$.

Each system in the comparison has two power converters: the field coil converter and the gun switch converter. The converters are responsible for controlling the self-excitation of the CPA and the power flow to the load. The size, weight, and complexity of the power converters are dependent on the performance requirement and the system topology. For the topologies considered here, these factors are common to both systems:

- the field converter is a full-wave, two-way bridge

- the gun switch is a half-wave, two-way converter

- the field converter must be controlled to reclaim magnetic energy, in order to return stored magnetic energy to the CPA rotor

In the RFSP system, railgun energy recovery occurs naturally as the CPA voltage swings negative when the projectile leaves the barrel. In the RFFP system, however, the gun converter must be controlled to invert the power flow and recover energy.

\section{CPA DESIGN AND PERFoRMANCE}

The three CPA systems under comparison are the CCEMG, the rotating-field single-phase (RFSP) CPA and the rotatingfield four-phase (RFFP) CPA. While each of the systems under comparison is assumed to store $40 \mathrm{MJ}$ and to drive the same load, differences in internal structure result in different design issues for each machine type.

\section{A. Cannon-caliber electric gun system (CCEMG)}

The CCEMG alternator is an air-core machine with a single-phase, rotating armature. The rotor is constructed by stacking tapered interference composite rings onto a titanium shaft. The armature winding is placed near the outer radius of the rotor. Its four-pole configuration minimized eddy current and allowed the use of a metal shaft.

When a single-phase system is used, the launcher is driven by a single pulse. The pulse width should, therefore, be such that the current is near or at zero at projectile exit. This coincidence helps to reduce off-axis forces on the projectile that adversely affect accuracy. The rotational speed of the rotor is constrained by the pulse width.

The armature winding on the rotor produced $800 \mathrm{kA}$ gun pulses at relatively high frequency. High current brushes and slip rings were required on the rotor. This current transfer mechanism required a significant development effort that resulted in heavy, bulky components.

The stator contains the field and compensating windings. Because the field winding is in the stator, conductors with a large cross-sectional area were used to minimize current density and heating. The self-excitation charge time is 70 to $100 \mathrm{~ms}$. The low-loss field coil design allowed this long charging time; therefore the voltage on the field coil converter was reduced and the designers were able to minimize its size. The compensating winding was wound so that its magnetic axis is aligned in quadrature with the field axis. The quadrature axis structure allows the field coil to charge at a fast rate without inducing undue losses in the compensating winding [7].

\section{B. Rotating-field single-phase CPA (RFSP)}

The limitations of the rotating-armature CCEMG were considered in the design of the RFSP. While the RFSP has not yet been built, its design concept will serve as an example to help understand the next step in the evolution of air-core machines. In the RFSP, the gun is still driven by a single pulse from the armature winding, but the field coil is placed on the rotor, which simplifies the brush and slip ring design and will result in hardware that is much less massive.

In trade for this advantage to the CPA, however, the field coil converter increases in mass because of these factors:

- field coil current density is significantly higher than for the stationary-field CPA because a lighter field winding is required for high-speed support from the composite banding

- the field coil must be charged quickly in order to keep efficiency acceptably high, and the higher power requirements result in a larger converter

This result illustrates that effective comparisons can be made only at the system level; CPA mass alone is not a useful discriminator.

A designer has more flexibility in the design of the rotor structure because the spinning rotor is stationary with respect to the excitation field and eddy currents in components such as the rotor shell are not an issue. The rotor shell can be made of titanium with layers of composite bandings and the field coil winding stacked on it. As a result, this rotor will operate at high energy density because the energy is stored in heavy components that spin at high velocity [8]. Quadrature compensation would also be used (the winding located on the rotor and as close as possible to the air gap) to provide protection from some transient fields produced by the armature winding during discharge.

\section{Rotating-field four-phase CPA (RFFP)}

Most of the design considerations that have been discussed for the RFSP apply to the RFFP design, with the exception of the armature winding, which is made up of four phases rather than one. The multiphase arrangement allows the machine speed to be decoupled from the railgun requirements (resulting in a significant reduction in CPA mass) as long as the electrical period of the CPA is shorter than the required railgun pulse width. The gun pulse in multiphase systems is synthesized from a number of armature pulses rectified by a converter. The higher allowable tip speed of multiphase machines allows for several structural enhancements within the rotor. Because railgun requirements tend to dictate CPA armature voltage levels, a full-wave converter is used to 
maximize the voltage applied to the field. As a result, field charging times are reduced and a higher charging efficiency for the CPA is attainable.

\section{CPA PERFORMANCE}

The design and performance parameters of the three CPA under study are summarized in Table 1. Fig. 2 shows the current pulse calculated for the three types of compulsators. It is apparent from observation of these plots that the current pulse produced by the RFFP is flatter and therefore has a lower peak-to-average ratio than the current pulses produced by the other two machines. The resulting improvement in piezometric efficiency (Table 1) allows a reduction in the parasitic mass of the projectile; more energy is imparted to the useful part of the projectile for the same amount of energy produced by the power system.

Fig. 3 shows the field charging current calculated for the three machines. The RFFP design charges fastest and, therefore, most efficiently. The RFSP is inefficient (Table 1) because its field current density is high but its armature voltage is low, requiring a long charging period for the RFSP field. An extra armature winding designed for efficient field charging, intended to overcome this deficiency, could be added to the rotor. This approach was used in the small caliber CPA, but it carried the added complication of an extra slip ring.

\section{Switch Design ANd Performance}

A preliminary design of a switching system was completed for the RFSF and RFFP systems and the design parameters are listed in Table 2. (Similar data for the CCEMG converter design were documented in [9]). The device used in each converter is a near-term developmental device that is based on a reasonable extension of current technology SCR [10]. The converters for the RFSP require fewer devices than do those of the RFFP and are consequently more reliable, less massive, and less voluminous. The main reasons for this result are

- each phase in a multiphase system must withstand the peak operating voltage and rate-of-current rise

- multiphase systems operate at higher electrical frequency than do single phase systems

- nearly four times as many devices are required to stand off voltage in the four-phase system

In assessing risk based on issues of device numbers, controls, and electrical stress, the RSFP is considered to be a lower-risk system than the RFFP. Single-phase gun switch converters have fewer devices to trigger and each device is triggered once per discharge simultaneously with all other devices. Inversion occurs naturally at projectile exit so no intervention from the controller is required. Multiphase switch converters are triggered multiple times per discharge; each phase must be triggered independently; and inversion must be controlled. System faults can be generated by signal cross talk, spurious signals from the controller, and trigger control failures. Furthermore, the devices in the gun switch converter operate at higher per-device nominal rate-of-current rise and voltage, making a single-device failure and resultant cascade failure more likely.

\section{COMPARISON SUMMARY}

\section{A. Mass}

A higher tip speed is possible for the RFFP (Table 1) because it does not use a single matched pulse to drive the railgun, and this enables a reduction of mass and volume. Mass of the RFSP could be reduced by switching from a 4pole to a 2-pole topology, but research indicates that actually implementing this configuration would be difficult $[2,4]$.

\section{B. Muzzle current}

The RFSP offers advantages in the natural current zero at muzzle exit and in the energy reclamation process which occurs during the gun pulse event. With the RFFP, additional switching and controls are required to zero large muzzle currents and reclaim vital magnetic gun energy. While the engineering concepts are in place for this inversion procedure, it has not yet been tested experimentally. The inverter mechanism and switches add mass to the RFFP, somewhat offsetting its advantage in this area over the RFSP.

\section{Current pulse shape}

The current pulse shape generated by the RFFP is superior to the shape created by the RFSP. The gun pulse from the RFFP is flatter and has a lower peak, so its piezometric efficiency is better. In addition, newer UT-CEM projectile testing observations has indicated that the current needs to be sustained at high levels late in the railgun pulse cycle, in order to extend the transition velocity of the armature contacts.

\section{Controls and Switching}

The RFSP has a clear advantage over the RFFP since there are fewer devices and, consequently, less mass and higher reliability. The natural occurrence of gun energy reclamation also simplifies controller functions.

\section{E. Efficiency}

It is important to recognize in this application gun performance (and not the field coil) defines generator voltage requirements. Though many factors (including reduced machine size and higher piezometric efficiency) play a role, the higher tip speed of the RFFP is critical in that it allows for reduced field coil amp-turn requirements, which results in its smaller size. The efficiency of the RFSP, however, could be increased with the addition of another armature winding which is optimized around charging the field winding only [2].

\section{CONCLUSIONS}

The RFFP appears to be the best technical solution for the railgun system, as reflected in table 3 . This result is based upon both piezometric and system efficiency and not onsystem weight, which was expected to be a significant advantage before the study was undertaken. In addition, the RFFP system scored 30\% higher in delivered energy density. Should it be possible, however, to improve RFSP efficiency 
as noted earlier, then selection of a CPA design to drive a cannon caliber class railgun will be more dependent upon railgun pulse shape desires and overall system reliability issues. These conclusions seem valid for high performance railgun systems with bore diameters of $<50 \mathrm{~mm}$; in higher caliber systems, volume and weight of the CPA are far more critical design factors.

\section{REFERENCES}

[1] M.D. Werst, D.E. Perkins, S.B. Pratap, M.L. Spann, R.F. Thelen, "Testing of a rapid fire, compensated pulsed alternator system," IEEE Transactions on Magnetics, Vol. 25, No. 1, January 1989.

[2] J.R. Kitzmiller, R.W. Faidley, R.N. Headifen, R.L. Fuller, R.F. Thelen, "Manufacturing and testing of an air-core compulsator driven 0.60 caliber railgun system," IEEE Transactions on Magnetics, Vol. 29, No. 1, January 1993.

[3] J.R. Kitzmiller, S.B. Pratap, M.D. Werst, C.E. Penney, T.J. Hotz, and B.T. Murphy, "Laboratory testing of the pulse power system for the cannon caliber electromagnetic gun system (CCEMG)," IEEE Transactions on Magnetics, vol. 31, no. 1, January 1995.
[4] A.W. Walls, et. al., "A field based, self-excited compulsator power supply for a 9 MJ railgun demonstrator," IEEE Transactions on Magnetics, vol. 27, no. 1, January 1991.

[5] S.K. Murthy, "Investigation of multiphase railgun systems", Ph.D. Dissertation, The University of Texas at Austin, Texas, December 1992.

[6] J.R. Kitzmiller, et. al., "Predicted versus actual performance of the model scale compulsator system", submitted to the $10^{\text {th }}$ EML Symposium.

[7] S.B. Pratap, "Limitations on the minimum charging time for the field coil of air core compensated pulsed alternators," IEEE Transactions on Magnetics, vol 27, No. 1, January, 1991.

[8] R. Acebal, "Energy storage capabilities of rotating machines including a comparison of laminated disk and rim rotor composite designs," IEEE Transactions on Magnetics, Vol. 35, No. 1, January 1999.

[9] T.J. Hotz, et. al., "Single shot switch performance on the cannon caliber electromagnetic gin program," IEEE Transactions on Magnetics, vol 35, No. 1, January, 1999.

[10] J.A. Pappas \& D. Piccone, "Power converters for railguns," to be published, IEEE Transactions on Magnetics, January 2001.

TABLE 1. TABULATED SYSTEM DESIGN PARAMETERS COMPARED

\begin{tabular}{lcccc}
\hline \multicolumn{1}{c}{ Design Parameter } & Units & CCEMG & RSFP & RFFP \\
\hline CPA weight & $\mathrm{kg}$ & 2,046 & 1,312 & 968 \\
Switch weight & $\mathrm{kg}$ & 415 & 260 & 544 \\
System weight & $\mathrm{kg}$ & 2,711 & 1,572 & 1,512 \\
Rotor tip speed & $\mathrm{m} / \mathrm{s}$ & 460 & 463 & 615 \\
System efficiency & $\%$ & 22 & 12 & 21 \\
Peak acceleration & $\mathrm{kgees}$ & 215 & 271 & 157 \\
Piezometric eff. & $\%$ & 28 & 38 & 66 \\
DED (per shot)* & $\mathrm{J} / \mathrm{g}$ & 0.23 & 0.43 & 0.56 \\
CPA voltage (L-L) & $\mathrm{kV}$ & 3.8 & 3.8 & 11 \\
Peak Current & $\mathrm{kA}$ & 790 & 900 & 700 \\
Current at exit & $\mathrm{kA}$ & $\sim 0$ & $\sim 0$ & $400+$ \\
Field coil MMF/pole & MA-turns & 1.6 & 2.1 & 2.03 \\
& /pole & & & \\
\hline
\end{tabular}

* Maximum energy delivered to railgun breech while projectile is inside the bore divided by the system mass

TABLE 2. SWITCH DESIGN PARAMETERS FOR SINGLE PHASE CONCEPT AND 4 PHASE CONCEPT

\begin{tabular}{|c|c|c|c|c|c|c|}
\hline & \multirow[b]{2}{*}{$\begin{array}{c}\text { Device } \\
\text { Limits } \\
\end{array}$} & \multicolumn{2}{|c|}{ RFSP } & \multicolumn{2}{|c|}{ RFFP } & \multirow[b]{2}{*}{ Units } \\
\hline & & $\begin{array}{c}\text { Worst-phase } \\
\text { operating } \\
\text { stress } \\
\end{array}$ & $\begin{array}{c}\text { Nominal } \\
\text { device } \\
\text { stress } \\
\end{array}$ & $\begin{array}{c}\text { Worst-phase } \\
\text { operating } \\
\text { stress } \\
\end{array}$ & $\begin{array}{c}\text { Nominal } \\
\text { device } \\
\text { stress } \\
\end{array}$ & \\
\hline \multicolumn{7}{|l|}{ Gun Switch Converter } \\
\hline Action per phase & $22.5 \times 10^{6}$ & $11.7 \times 10^{9}$ & $22.1 \times 10^{6}$ & $2.6 \times 10^{9}$ & $21.8 \times 10^{6}$ & $\mathrm{~A}^{2} \mathrm{~s}$ \\
\hline Critical dI/dt & $1.5 \times 10^{9}$ & $1.7 \times 10^{9}$ & $73.9 \times 10^{6}$ & $2.2 \times 10^{9}$ & $200.0 \times 10^{6}$ & $\mathrm{~A} / \mathrm{s}$ \\
\hline Vdrm/rrm & $9.0 \times 10^{3}$ & $2.2 \times 10^{3}$ & $2.2 \times 10^{3}$ & $7.3 \times 10^{3}$ & $3.7 \times 10^{3}$ & $\mathrm{~V}$ \\
\hline Total \#.devices per phase & & & 23 & & 88 & \\
\hline Converter Mass & & & 92 & & 352 & $\mathrm{~kg}$ \\
\hline \multicolumn{7}{|l|}{ Field Coil Converter } \\
\hline Action per phase & $22.5 \times 10^{6}$ & $9.4 \times 10^{9}$ & $21.3 \times 10^{6}$ & $30.0 \times 10^{6}$ & $7.5 \times 10^{6}$ & $\mathrm{~A}^{2} \mathrm{~s}$ \\
\hline Critical di $/ \mathrm{dt}$ & $1.5 \times 10^{9}$ & $1.4 \times 10^{9}$ & $66.7 \times 10^{6}$ & $725.0 \times 10^{6}$ & $362.5 \times 10^{6}$ & $\mathrm{~A} / \mathrm{s}$ \\
\hline Vdrm/rrm & $9.0 \times 10^{3}$ & $4.3 \times 10^{3}$ & $4.3 \times 10^{3}$ & $10.0 \times 10^{3}$ & $3.3 \times 10^{3}$ & $\mathrm{~V}$ \\
\hline Total \#. Devices per phase & & & 42 & & 48 & \\
\hline Converter Mass & & & 168 & & 192 & $\mathrm{~kg}$ \\
\hline
\end{tabular}


TABLE 3. COMPULSATOR SYSTEM DOWNSELECT RESULTS

\begin{tabular}{lcc}
\hline System Significant Parameter & Single Phase & Multi-Phase \\
\hline Compulsator Weight/Size & & $\sqrt{ }$ \\
Switch Weight/Size & $\sqrt{ }$ & \\
System Weight/Size & $\sqrt{ }$ & $\sqrt{ }$ \\
Delivered Energy Density & & $\sqrt{ }$ \\
System Efficiency & $\sqrt{ }(\mathrm{a})$ & $\sqrt{ }$ \\
Muzzle Current & $\sqrt{ }$ & \\
Piezometeric Efficiency & & $\sqrt{ }$ \\
Reliability & $\sqrt{ }$ \\
\hline
\end{tabular}

(a) system efficiency can likely be improved on single phase system

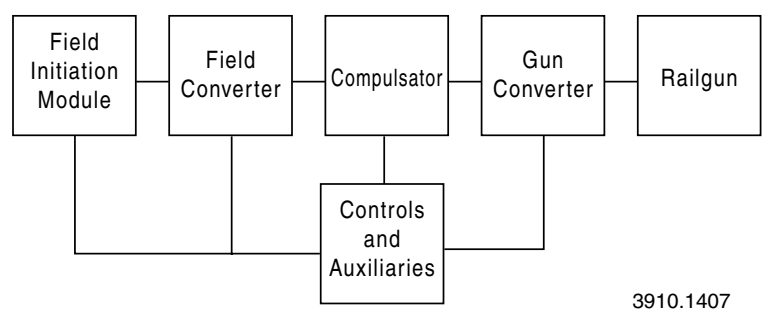

Fig. 1. Principal hardware components for a compulsator railgun system

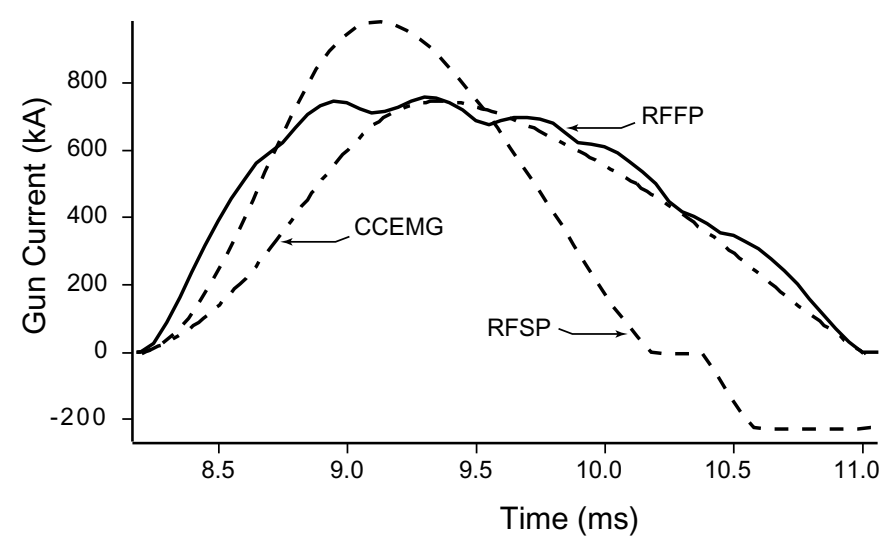

3910.1408

Fig. 2. Simulated gun current profiles from the studied machines 


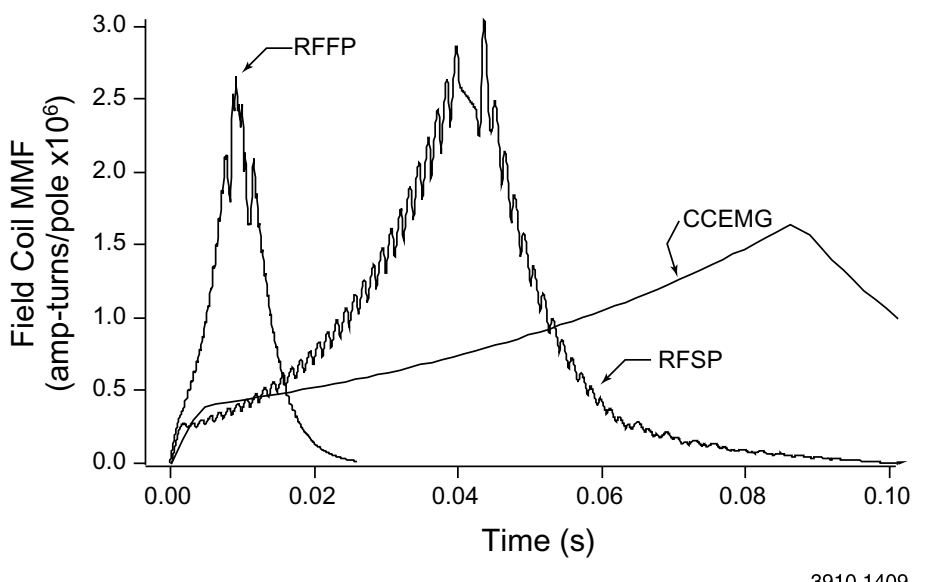

Fig. 3. Simulated field coil current profiles shown as $\mathrm{mmf} /$ pole for the studied machines 